\title{
Assessing Genetic Diversity among Foxtail millet (Setaria italica (L.) P. Beauv.) Accessions Using RAPD and ISSR Markers
}

\author{
Smita Shingane ${ }^{1^{*}}$, J. V. Patil ${ }^{1}$, Sunil Gomashe ${ }^{2}$ and Dinesh Chand ${ }^{2}$
}

${ }^{1}$ Dept. of Genetics and Plant Breeding, Mahatma Phule Krishi Vidyapeeth (MPKV), Rahuri, Maharashtra (413 722 ), India

${ }^{2}$ ICAR-National Bureau of Plant Genetic Resources (ICAR-NBPGR), Regional Station, Akola, Maharashtra (444 104), India

\section{Corresponding Author}

Smita Shingane

e-mail:smita_mitu25@rediffmail.com

\author{
Article History \\ Article ID: 3 C0574 \\ Received in $29^{\text {th }}$ October, 2017 \\ Received in revised form $19^{\text {th }}$ December, 2017 \\ Accepted in final form $1^{\text {st }}$ February, 2018
}

\begin{abstract}
Foxtail millet [Setaria italica (L.) P. Beauv.], is an important grain crop in temperate, subtropical, tropical Asia and in parts of southern Europe. In India it is cultivated in Andhra Pradesh, Karnataka, Tamil Nadu, Rajasthan, Madhya Pradesh and some parts of Maharashtra. The present study was conducted to analyse the molecular diversity in the foxtail millet genotypes by using RAPD and ISSR markers and identify diverse accessions for use in varietal improvement programmes. A set of 44 foxtail millet accessions selected from Kolhapur (Western Maharashtra) region of India were analyzed using random amplified polymorphic DNA (RAPD) and inter simple sequence repeat (ISSR) markers. A total of 212 (135 RAPD and 77 ISSR) scoreable markers were generated with 29 RAPD and 19 ISSR primers. Average number of alleles generated by RAPD was 7.1 and ISSR was 6.41. Per cent polymorphism shown by RAPD primers varied from $62.50 \%$ to $100 \%$ and ISSR from $66.66 \%$ to $100 \%$. The average PIC value for RAPD and ISSR was 0.74 and 0.73 , respectively. The dendrogram generated using UPGMA revealed three major clusters, with 22 genotypes in one cluster and 20 genotypes in second cluster and two genotypes in third cluster. The genetic similarity matrices based on the Jaccard's coefficient ranged from 0.374 to 0.964 and 0.35 to 0.98 for RAPD and ISSR, respectively. The genotypes KOFM 1, KOFM 14, KOFM 36, KOFM 89, KOFM 90, KOFM 94 and KOFM 95 were found superior for creating more variability in foxtail millet.
\end{abstract}

Keywords: Genetic diversity, Land races, dendrogram, molecular markers

\section{Introduction}

Foxtail millet [Setaria italica (L.) P. Beauv.], is also known as Italian millet, Kangu, Kangani, Kalakangani, Koni, Rala and Kaon in different parts of India. It is the second most widely grown species amongst millets and important grain crop in temperate, subtropical, tropical Asia and in parts of southern Europe. China, India and Japan are the major foxtail millet growing countries in the world. According to Vavilov (1926), the principal centre of diversity for foxtail millet is East Asia, including China and Japan. In China, foxtail millet is the most common millet and one of the main food crops, especially among the low income groups in dry northern parts of the country. Foxtail millet is known for its drought tolerance in India and several countries. At present it is cultivated in Andhra Pradesh, Karnataka, Maharashtra, Tamil Nadu, Rajasthan, Madhya Pradesh, and some parts of Maharashtra. Foxtail millet is largely a self pollinated crop with cross pollination averaging about 4 per cent (Li et al., 1935). Foxtail millet is mixed with legumes to make porridge and also mixed with soybean to make mixed flour. Foxtail millet has low glycemic index (GI), used for preparation of low GI biscuits and burfi, a sweet product, and it is an ideal food for people suffering from diabetes (Thathola et al., 2010, Anju and Sarita, 2010, Wang et al., 2016). Foxtail millet is also fermented to make vinegar, yellow wine, maltose, beer and other related products. It is also used for feeding cage birds and by-product of the foxtail millet is used as animal feed. The foxtail millet grain is rich in protein $\left(11.2 \mathrm{~g} 100 \mathrm{~g}^{-1}\right)$ and iron (2.8 $\mathrm{mg}$ ) as compared to rice.

Morphological characterization does not reliably portray the genetic relationships among the genotypes because of environmental interactions, unknown genetic control of the traits and inadequate sampling of the genome in terms of phenotype. Thus, for genetic diversity assessment, molecular markers offer considerable advantages over the morphological markers (Reddy et al., 2006; Chander et al., 2017; Ramesh et al., 2017).

The diversity studies at molecular level in foxtail millet are very meagre and were mainly based on RFLP analysis (Fukunaga et al., 2002), using these markers they have concluded that the 
foxtail millet landrace belonging to China were more variable. The RAPD markers used in some earlier studies (Li et al., 1998, Schontz and Rether 1999). Till recently the co-dominat marker systems like microsatellites were not available in foxtail millet. RatnaKumari et al., 2011, used inter simple sequence repeats (ISSR) for diversity analysis. During our investigation also the co-dominant markers were not available; the analysis was done using ISSR and RAPDs. In last 4-5 years number of studies have been performed using SSR and EST-SSRs for genetic diversity analysis in foxtail millet ( Goron and Raizada, 2015, Ali et al., 2016, Wang et al., 2016, Andesen and Nepal, 2017, Chander et al., 2017).

\section{Materials and Methods}

\subsection{Plant material, DNA extraction and purification}

Forty-four genotypes for the present investigation were collected from the Millet Breeder, All India Coordinated Research Project on Small Millets (AICRP on SM), NARP, Shenda Park, Kolhapur. The list of genotypes used is given with their pedigree in Table 1. Seeds of 44 genotypes were sown in greenhouse and about 1-2 g of young healthy leaves per genotype were harvested from 15 to 20 days old seedlings for DNA isolation method given by Li et al. (1998) for RAPD and Reddy et al. (2009) for ISSR with some modifications.

After quantification, a working DNA stock of concentration of $5 \mathrm{ng}^{-1}$ was prepared and stored at $4{ }^{\circ} \mathrm{C}$ until use. For PCR amplification 29 RAPD primers and 20 ISSR primers from the commercial kits obtained from Operon Technologies Inc., Alameda, USA were screened. Out of these 19 RAPD and 12 ISSR were found polymorphic (Table 2). PCR amplification was optimized and conducted in a reaction buffer of $25 \mu \mathrm{l}$ containing 10X PCR buffer B for RAPD; 10X buffer F for ISSR; 1 Unit Taq DNA polymerase; $0.2 \mathrm{mM}$ each of dATP, dGTP, dCTP and dTTP; $25 \mathrm{mM}$ of $\mathrm{MgCl} 2$ (all these reagents from Life Technologies, India), $1 \mu \mathrm{M}$ of respective primer and $20 \mathrm{ng}$ of genomic DNA. PCR amplification was carried out in Thermal Cycler (Eppendorf, Master cycler gradient, Germany). The thermal cycling conditions for RAPD were as follows: initial denaturation at $94{ }^{\circ} \mathrm{C}$ for $5 \mathrm{~min}$, followed by 44 cycles of denaturation $\left(94^{\circ} \mathrm{C}\right)$ for $1 \mathrm{~min}$, annealing $\left(37^{\circ} \mathrm{C}\right)$ for $1 \mathrm{~min}$, primer extension $\left(72^{\circ} \mathrm{C}\right)$ for $2 \mathrm{~min}$, followed by an extension at $72{ }^{\circ} \mathrm{C}$ for $5 \mathrm{~min}$. For ISSR the cycling conditions were as follows: initial denaturation at $94{ }^{\circ} \mathrm{C}$ for $5 \mathrm{~min}$, followed by 40 cycles of denaturation $\left(94^{\circ} \mathrm{C}\right)$ for $30 \mathrm{sec}$, annealing $(45-55$ ${ }^{\circ} \mathrm{C}$ ) for $30 \mathrm{sec}$, primer extension $\left(72^{\circ} \mathrm{C}\right)$ for $30 \mathrm{sec}$, followed by an extension at $72{ }^{\circ} \mathrm{C}$ for $10 \mathrm{~min}$. The amplification products of both RAPD and ISSR were analyzed by electrophoresis on $1.2 \%$ agarose gel stained with ethidium bromide (10 $\mathrm{mg} / \mathrm{ml}$ ) and photographed under UV transilluminater in gel documentation system (Flour Chem. TM Alpha Innotech, USA). A 100 bp plus DNA ladder (MBI Fermentas, Germany) was used as standard.

\subsection{Data analysis}

\begin{tabular}{|c|c|c|}
\hline Sr. No. & Genotype & Pedigree \\
\hline 1. & KOFM 1 & $\begin{array}{l}\text { Local collection from Western Maha- } \\
\text { rashtra, India }\end{array}$ \\
\hline 2 & KOFM 2 & Local collection \\
\hline 3. & KOFM 6 & Local collection \\
\hline 4. & KOFM 14 & Local collection \\
\hline 5 & KOFM 17 & Local collection \\
\hline 6. & KOFM 18 & Local collection \\
\hline 7. & KOFM 24 & SIA 3043 \\
\hline 8. & KOFM 25 & Sel from SIA 326 \\
\hline 9. & KOFM 28 & SIA 3039 \\
\hline 10. & KOFM 29 & SIA 3044 \\
\hline 11. & KOFM 33 & GPUS 27 \\
\hline 12. & KOFM 36 & GPUS 30 \\
\hline 13. & KOFM 37 & CO 5×TNAU 200 \\
\hline 14 & KOFM 41 & SIA 3035 \\
\hline 15. & KOFM 42 & Local collection \\
\hline 16. & KOFM 44 & Local collection \\
\hline 17. & KOFM 46 & Local collection \\
\hline 18. & KOFM 48 & Local collection \\
\hline 19. & KOFM 51 & Local collection \\
\hline 20. & KOFM 52 & Local collection \\
\hline 21. & KOFM 53 & Local collection \\
\hline 22. & KOFM 54 & Local collection \\
\hline 23 & KOFM 55 & Local collection \\
\hline 24. & KOFM 58 & Local collection \\
\hline 25. & KOFM 59 & Local collection \\
\hline 26. & KOFM 61 & Local collection \\
\hline 27. & KOFM 62 & Local collection \\
\hline 28. & KOFM 64 & Local collection \\
\hline 29. & KOFM 65 & Local collection \\
\hline 30. & KOFM 66 & Local collection \\
\hline 31. & KOFM 70 & Local collection \\
\hline 32. & KOFM 73 & Local collection \\
\hline 33. & KOFM 77 & Local collection \\
\hline 34. & KOFM 79 & Local collection \\
\hline 35. & KOFM 80 & Local collection \\
\hline 36. & PS 4 & Mutant of 543/ Sie 2616 \\
\hline 37 & GPUS 28 & UAS Bangalore, India \\
\hline 38. & SIA 326 & Pureline selection from Mandya \\
\hline 39. & KOFM 88 & Sie 1472 UK \\
\hline
\end{tabular}

Continue... 


\begin{tabular}{lll}
\hline Sr. No. & Genotype & Pedigree \\
\hline 40. & KOFM 89 & Sie 1537 \\
41. & KOFM 90 & Sie 1539 \\
42. & KOFM 93 & Sie 1541 \\
43. & KOFM 94 & Sie 1598 \\
44. & KOFM 95 & Sie 1599 \\
\hline
\end{tabular}

Table 2: List of RAPD primers used with their sequences

\begin{tabular}{|c|c|c|}
\hline Sr. No. & Primer code & $5 \mid$ to $3 \mid$ \\
\hline 1. & OPA 3 & AGTCAGCCAC \\
\hline 2. & OPD 1 & ACCGCGAAGG \\
\hline 3. & OPD 5 & TGAGCGGACA \\
\hline 4. & OPD 11 & GAGTCTCAGG \\
\hline 5. & OPD 18 & GAGAGCCAAC \\
\hline 6. & OPE 3 & CCAGATGCAC \\
\hline 7. & OPE 4 & GTGACATGCC \\
\hline 8. & OPE 9 & CTTCACCCGA \\
\hline 9. & OPE 12 & TTATCGCCCC \\
\hline 10. & OPE 13 & CCCGATTCGG \\
\hline 11. & OPE 15 & ACGCACAACC \\
\hline 12. & OPE 17 & CTACTGCCGT \\
\hline 13. & OPE 18 & GGACTGCAGA \\
\hline 14. & OPE 19 & ACGGCGTATG \\
\hline 15. & OPK 9 & CCCTACCGAC \\
\hline 16. & OPL 2 & TGGGCGTCAA \\
\hline 17. & OPL 11 & ACGATGAGCC \\
\hline 18. & OPL 14 & GTGACAGGCT \\
\hline 19. & OPL 15 & AAGAGAGGGG \\
\hline 20. & OPL 16 & AGGTTGCAGG \\
\hline 21. & OPL 18 & ACCACCCACC \\
\hline 22. & OPM 5 & GGGAACGTGT \\
\hline 23. & OPM 9 & GTCTTGCGGA \\
\hline 24. & OPM 10 & TCTGGCGCAC \\
\hline 25. & OPM 12 & GGGACGTTGG \\
\hline 26. & OPM 14 & AGGGTCGTTC \\
\hline 27. & OPM 17 & TCAGTCCGGG \\
\hline 28. & OPM 18 & CACCATCCGT \\
\hline 29. & OPM 20 & AGGTCTTGGG \\
\hline
\end{tabular}

The RAPD and ISSR products were scored as presence (1) or absence of band $(0)$ in all samples for each primer genotype combination. A binary data matrix based on presence/absence was used for analysis with NTSYSpc Software Package (Rohlf 1997). The polymorphism information content (PIC) value was calculated as $P I C=\Sigma\left(1-P i^{2}\right) / n$ where, $n$ is the number of band positions analyzed in the set of accessions and $P i$ is the frequency of $i^{\text {th }}$ pattern. Jaccards similarity Coefficient was used for the construction of dendrogram by the Unweighted Pair Group Method using Arithmetic Mean (UPGMA).

\section{Results and Discussion}

In view of the several merits of this crop and very limited research undergone, there is a need for the study of genetic and molecular diversity for its effective utilization in development of improved cultivars. Therefore, the present investigation was formulated to study the molecular diversity present in the genotypes by using RAPD and ISSR markers in foxtail millet.

Out of 29 RAPD and 20 ISSR primers surveyed, 19 RAPD and 12 ISSR primers were selected for the present study based on the extent of polymorphism observed in the amplicons. The amplification obtained with RAPD and ISSR primers was good and consistent (Table 3 and 4). A total of 212 scoreable amplification products (135 RAPD and 77 ISSR)

Table 3: Sequences and fixed optimum annealing temperature for ISSR primers used in ISSR analysis

\begin{tabular}{|c|c|c|c|}
\hline $\begin{array}{l}\text { Sr. } \\
\text { No. }\end{array}$ & $\begin{array}{l}\text { ISSR } \\
\text { primers }\end{array}$ & Sequence of primers $\left(5^{\prime}-3^{\prime}\right)$ & OAT \\
\hline 1. & ISSR 807 & AGAGAGAGAGAGAGAGT & 42.4 \\
\hline 2. & ISSR 808 & AGAGAGAGAGAGAGAGC & 46.8 \\
\hline 3. & ISSR 809 & AGAGAGAGAGAGAGAGG & 46.3 \\
\hline 4. & ISSR 810 & GAGAGAGAGAGAGAGAT & 42.8 \\
\hline 5. & ISSR 811 & GAGAGAGAGAGAGAGAC & 43.2 \\
\hline 6. & ISSR 816 & CACACACACACACACAT & 51.0 \\
\hline 7. & ISSR 817 & CACACACACACACACAA & 52.7 \\
\hline 8. & ISSR 819 & GTGTGTGTGTGTGTGTA & 47.8 \\
\hline 9. & ISSR 820 & GTGTGTGTGTGTGTGTC & 50.5 \\
\hline 10. & ISSR 822 & ТСТСТСТСТСТСТСТСА & 45.7 \\
\hline 11. & ISSR 823 & ТСТСТСТСТСТстСТСС & 47.3 \\
\hline 12. & ISSR 826 & ACACACACACACACACC & 53.1 \\
\hline 13. & ISSR 834 & AGAGAGAGAGAGAGAGYT & 45.1 \\
\hline 14. & ISSR 835 & AGAGAGAGAGAGAGAGYC & 45.7 \\
\hline 15. & ISSR 840 & GAGAGAGAGAGAGAGAYT & 45.7 \\
\hline 16. & ISSR 841 & GAGAGAGAGAGAGAGAYG & 46.1 \\
\hline 17. & ISSR 880 & GGAGAGGAGAGGAGA & 49.0 \\
\hline 18. & ISSR 885 & BHBGAGAGGAGAGAGAGA & 46.4 \\
\hline 19. & ISSR 890 & VHVGTGTGTGTGTGTGT & 51.0 \\
\hline 20. & ISSR 891 & HVHTGTGTGTGTGTGTG & 51.9 \\
\hline
\end{tabular}

OAT: Optimum annealing Temp. $\left({ }^{\circ} \mathrm{C}\right)$; Single letter abbreviations for mixed base positions: Y: (C, T); B: (C, G, T i.e. not $A)$; H: (A, C, T i.e. not G); V: (A, C, G i.e. not T) 


\begin{tabular}{|c|c|c|c|c|c|c|}
\hline $\begin{array}{l}\text { Sr. } \\
\text { No. }\end{array}$ & Primer & TNBG & TNMB & TNPB & PP & $\begin{array}{c}\text { PIC Val- } \\
\text { ues }\end{array}$ \\
\hline 1. & OPA 03 & 4 & 0 & 4 & 100.00 & 0.440 \\
\hline 2. & OPD 05 & 8 & 1 & 7 & 87.50 & 0.789 \\
\hline 3. & OPE 03 & 9 & 2 & 7 & 77.77 & 0.529 \\
\hline 4. & OPE 04 & 7 & 0 & 7 & 100.00 & 0.701 \\
\hline 5. & OPE 15 & 5 & 0 & 5 & 100.00 & 0.701 \\
\hline 6. & OPE 18 & 5 & 0 & 5 & 100.00 & 0.754 \\
\hline 7. & OPE 19 & 5 & 0 & 5 & 100.00 & 0.704 \\
\hline 8. & OPK 09 & 10 & 1 & 9 & 90.00 & 0.882 \\
\hline 9. & OPL 02 & 6 & 0 & 6 & 100.00 & 0.613 \\
\hline 10. & OPL 14 & 7 & 0 & 7 & 100.00 & 0.797 \\
\hline 11. & OPL 18 & 6 & 0 & 6 & 100.00 & 0.707 \\
\hline 12. & OPM 05 & 8 & 3 & 5 & 62.50 & 0.849 \\
\hline 13. & OPM 09 & 6 & 1 & 5 & 83.33 & 0.787 \\
\hline 14. & OPM 10 & 11 & 0 & 11 & 100.00 & 0.878 \\
\hline 15. & OPM 12 & 8 & 0 & 8 & 100.00 & 0.814 \\
\hline 16. & OPM 14 & 7 & 1 & 6 & 85.71 & 0.651 \\
\hline 17. & OPM 17 & 8 & 0 & 8 & 100.00 & 0.816 \\
\hline 18. & OPM 18 & 7 & 0 & 7 & 100.00 & 0.779 \\
\hline 19. & OPM 20 & 8 & 3 & 5 & 62.50 & 0.838 \\
\hline Total & & 135 & 12 & 123 & 91.11 & -- \\
\hline
\end{tabular}

TNBG: Total number of band generated; TNMB: Total number of monomorphic bands; TNPB: Total number of polymorphic bands; PP: Per cent Polymorphism (\%)

were generated. The number of amplicons generated by each primer varied from four (OPA 03) to eleven (OPM 10) for RAPDs with an average of 7.1 amplicons per primer and four (ISSR 807, ISSR 809 and ISSR 811) to nine (ISSR 810 and ISSR 823) for ISSRs. Average number of alleles generated by ISSR was 6.41. The average number of polymorphic bands amplified for each primer (7.1) recorded in the present study were comparable with the earlier reports in foxtail millet by Li et al. (1998) (7.78), Schontz and Rether (1998) (6.25); Ratna Kumari et al. (2011) (7.18) in foxtail millet and Fakrudin et al., (2004) (6.86), Kumari and Pande, (2010) (6.64) in finger millet. While Gupta et al. (2010) reported 8.5 bands per primer in finger millet which were higher than that obtained in the present study.

Percent polymorphism shown by RAPD primers varied from 62.50 to $100 \%$. It was found that, total 135 bands were generated by amplification out of which 123 were polymorphic with an average of $91.11 \%$ polymorphism. Similar results were recorded by Li et al., (1998) using 19
RAPD primers in 20 accession of foxtail millet with $72.80 \%$ polymorphism. Fakrudin et al. (2004) used RAPD primers among 12 selected finger millet accessions and reported $85.82 \%$ polymorphism. Similarly, KalyanBabu et al. (2006) have reported $91 \%$ polymorphism among 32 finger millet accessions using 50 RAPD primers. In ISSR analysis out of 77 bands, 72 were polymorphic with an average of $93.50 \%$ polymorphism. RatnaKumari et al. (2011) also reported similar values for percent polymorphism (37.5 to 100) using RAPD and ISSR markers in foxtail millet.

The polymorphic information content (PIC) value as a relative measure of polymorphism level ranged between 0.440 (OPA 03) to 0.882 (OPK 09) in RAPD and it was ranged between 0.466 (ISSR 807) to 0.847 (ISSR 810) for ISSR. The average PIC value for RAPD (0.74) and ISSR (0.73) was higher than that of Jia et al. (2009) (0.69 for SSR) in foxtail millet and Panwar et al. (2010) (0.35 and 0.505 for RAPD and SSR, respectively) and Gupta et al. (2010) (0.51 and 0.19 for RAPD and ISSR, respectively) in finger millet. It was similar to that of Liu et al. (2011) ( 0.72 for SSR) in foxtail millet.

The higher PIC value indicated the informativeness of the primer. Among the primers used in the study three primers each from RAPD (OPK 09, OPM 10 and OPM 05) and ISSR (ISSR 810, ISSR 823 and ISSR 808) exhibited the PIC values from 0.882 to 0.816 . These primers can provide the basis for foxtail millet DNA profiling system. To examine the genetic relationship among the 44 foxtail millet genotypes under study based on the RAPD and ISSR results, the data scored from 19 RAPD and 12 ISSR primers were compiled and analyzed separately using NTSYS Pc programme (Rohlf,1997) (Table 5). The similarity matrix was computed using RAPD and ISSR markers based on Jaccard's coefficient. The genetic similarity

Table 5: Per cent polymorphism shown by different ISSR primers

\begin{tabular}{lcccccc}
\hline $\begin{array}{l}\text { Sr. } \\
\text { No. }\end{array}$ & Primer & TNBG & TNMB & TNPB & PP & $\begin{array}{c}\text { PIC } \\
\text { values }\end{array}$ \\
\hline 1. & ISSR 807 & 5 & 1 & 4 & 80.00 & 0.466 \\
2. & ISSR 808 & 8 & 2 & 6 & 75.00 & 0.816 \\
3. & ISSR 809 & 6 & 2 & 4 & 66.66 & 0.725 \\
4. & ISSR 810 & 9 & 0 & 9 & 100.00 & 0.847 \\
5. & ISSR 811 & 4 & 0 & 4 & 100.00 & 0.702 \\
6. & ISSR 817 & 5 & 0 & 5 & 100.00 & 0.749 \\
7. & ISSR 820 & 5 & 0 & 5 & 100.00 & 0.703 \\
8. & ISSR 823 & 9 & 0 & 9 & 100.00 & 0.839 \\
9. & ISSR 826 & 6 & 0 & 6 & 100.00 & 0.732 \\
10. & ISSR 834 & 8 & 0 & 8 & 100.00 & 0.745 \\
11. & ISSR 880 & 7 & 0 & 7 & 100.00 & 0.779 \\
12. & ISSR 885 & 5 & 0 & 5 & 100.00 & 0.703 \\
Total & & 77 & 5 & 72 & 93.50 & -- \\
\hline
\end{tabular}


matrices based on the Jaccard's coefficient ranged from 0.374 to 0.964 and 0.35 to 0.98 for RAPD and ISSR, respectively. The genetic similarity matrix also revealed that the KOFM 95 and KOFM 14, KOFM 94and KOFM 37 and KOFM 41 were distantly related which was indicated from the lowest genetic similarity coefficient (0.374), while KOFM 95 and KOFM 94 were closely related with a genetic similarity coefficient of 0.964 .

Interestingly, the dendrograms generated based on UPGMA method of cluster analysis using RAPD and ISSR marker data revealed exactly similar grouping of genotypes into three major clusters (Figure 1 and Figure 2, respectively). Cluster I comprised of two sub clusters of which KOFM 1, KOFM 28, KOFM 29, KOFM 36, KOFM 33, KOFM 48, KOFM 53, KOFM 54, KOFM 51 and KOFM 52 were in a separate sub cluster, while

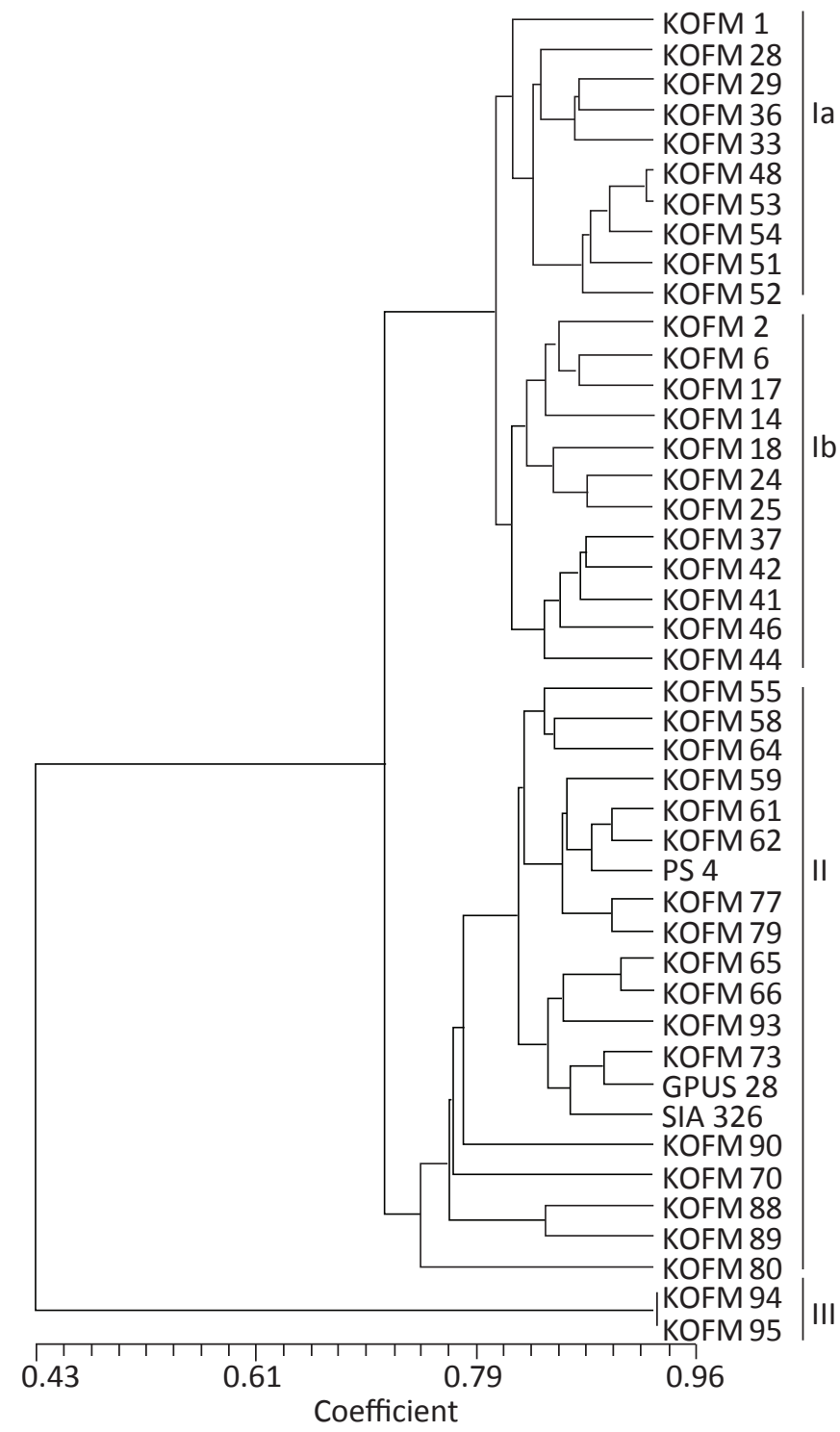

Figure 1: Dendrogram constructed with NTSYSpc ver.2.02 using UPGMA clustering algorithm from the pair-wise genetic similarity matrix to compare 44 foxtail millet genotypes based on allelic information from 19 RAPD markers

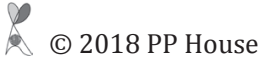


genotypes exhibited high similarity value (0.967).

\section{Conclusion}

Considerable diversity existed among the foxtail millet accessions studied. This study identified diverse genotypes viz., KOFM 95, KOFM 14, KOFM 94, KOFM 37 and KOFM 41 for use in hybridization program for foxtail millet improvement.

\section{References}

Ali, A., Choi, Y.M., Do, Y.H., Lee, S., Oh, S., Park, H.J., Cho, Y.H., Lee, M.C., 2016. EST-SSR Based.

Andersen, E., Nepal, M.P.,2017. Genetic diversity of disease resistance genes in foxtail millet (Setaria italica L.). Plant Gene 10, 8-16.

Anju, T., Sarita S., 2010. Suitability of foxtail millet (Setaria italica) and barnyard millet (Echinochloa frumentacea) for development of low glycemic index biscuits. Malaysian Journal ofNutrition 16, 361-368.

Chander, S., Bhat, K.V., Kumari, R., Sen, S., Gaikwad, A.B., Gowda, M.V.C., Dikshit, N., 2017. Analysis of spatial distribution of genetic diversity and validation of Indian foxtail millet core collection. Physiol Mol Biol Plants. 23, 663.

Fakrudin, B., Kulkarni, R.S., Shashidhar, H.E., Hittalmani, S., 2004. Genetic diversity assessment of finger millet, Eleucine coracana (Gaertn), germplasm through RAPD analysis. Plant Genetic Resources Newsletter 138, 50-54.

Fukunaga, K., Wang, Z., Kato, K., Kawase, M., 2002. Geographical variation of nuclear genome RFLPs and genetic differentiation in foxtail millet, Setaria italica (L.) P. Beauv. Genetic Resources and Crop Evolution 49, 95-101.

Genetic Diversity and Population Structure among Korean Landraces of Foxtail Millet (Setaria italica L.). Korean Journal of Plant Resources 29(3), 322-330.

Goron, T.L., Raizada, M.N., 2015. Genetic diversity and genomic resources available for the small millet crops to accelerate a New Green Revolution. Frontiers in Plant Science 6(157), 1-18.

Gupta, R., Verma, K., Joshi, D.C., Yadav, D., Singh, M., 2010. Assessment of genetic relatedness among three varieties of finger millet with variable seed coat colour using RAPD and ISSR markers. Genetic Engineering and Biotechnology Journal 2010 : GEBJ-2, http:// astonjournals.com/gebj.

Jia, X., Zhang, Z., Liu, Y., Zhang, C., Shi, Y., Song, Y., Wang, T. Li, Y., 2009. Development and genetic mapping of SSR markers in foxtail millet [Setaria italic (L.) P. Beauv.]. Theoretical. Applied Genetics 118, 821-829.

Kalyan Babu, B., Senthil, N., Gomez, S.M., Biji, K.R., Rajendraparasad, N.S., Satheesh Kumar, N., Chandrababu, R., 2006. Assessment of genetic diversity among finger millet accessions using molecular markers. Genetic Resources and Crop Evolution 54, 399-404.
Kumari Kanchan, Anita Pande., 2010. Study of genetic diversity in finger millet using RAPD markers. African Journal of Biotechnology 9, 4542-4549.

Li, H., Meng, W. J., Liu, T. M., 1935. Problems in the breeding of millet [Setaria italica (L.) Beauv]. Journal of American Society of Agronomy 27, 426-438.

Li, Y., Jia, J., Wang, Y., Wu, S., 1998. Intraspecific and interspecific variation in Setaria revealed by RAPD analysis. Genet Resources and Crop Evolution 45, 279-285.

Liu, Z., Bai, G., Zhang, D., Zhu, C., Xia, X., Cheng, R., Shi, Z., 2011. Genetic diversity and population structure of elite foxtail millet [Setaria italica (L.) P. Beauv.] germplasm in China. Crop science 51(4), 1655-1663.

Panwar, P., Nath, M., Yadav, V., Kumar, A., 2010. Comparative evolution of genetic diversity using RAPD, SSR and cytochrome $\mathrm{P} 450$ gene based markers with respect to calcium content in finger millet. Journal of Genetics 89: 121-133.

Ramesh, P., Kola, G., Gunti, M., Reddy, P.C.O., Banavath, J.N., Akila, C.S., 2017. Comprehensive phenotypic and statistical based analysis of Foxtail Millet (Setaria italica L.) lines for parental line selection. Annals of Plant Sciences 6, 1736-1741.

Ratna K., Dikshit, N., Sharma, D., Bhat, K.V., 2011. Analysis of molecular genetic diversity in a representative collection of foxtail millet [Setaria italica (L.) P. Beauv.] from different agro-ecological regions of India. Physiology and Molecular Biology of Plants 17, 363-374.

Reddy, V.G., Upadhyaya, H. D., Gowda, C.L.L., 2006. Characterization of world's Foxtail Millet germplasm collections for morphological traits. International Sorghum and Millets Newsletter 47, 107-109.

Rohlf, F.J., 1997. NTSYS-Pc. Numerical taxonomy and multivariate analysis system version 2.02e. Exeter Software, New York.

Schontz, D., Rether, B., 1999. Genetic variability in foxtail millet, Setaria italica (L.) P. Beauv.: Identification and classification of lines with RAPD markers. Plant Breeding 118, 190-192.

Schontz, D., Rether, B., 1998. Genetic variability in foxtail millet, Setaria italica (L.) P. Beauv. RFLP using a heterologous rDNA probe. Plant Breeding 117, 231-234.

Thathola, A., Srivastava, S., Singh, G., 2010. Effect of foxtail millet (Setaria italica) supplementation on serum glucose, serum lipids and glycosylated hemoglobin in type 2 diabetics. DiabetologiaCroatica 40, 23-28.

Vavilov, N.I., 1926. Studies on the origin of cultivated plants, p. 248. InstAppl Bot Plant Breed, Leningrad.

Wang, H.G., Jia, G.Q., Zhi, H., Wen, Q.F., Dong, J.L., Chen, L., Wang, J.J., Cao, X.N., Liu, S.C., Wang, L., Qiao, Z.J., Diao, X.M., 2016. Phenotypic Diversity Evaluations of Foxtail Millet Core Collections. Acta Automatica Sinica 42(1), 19-30. 